Archived version from NCDOCKS Institutional Repository http://libres.uncg.edu/ir/asu/

\title{
Appalachỉan
}

B O O N E, N O R T H C A R O L I N A

\section{Communicating How Water Works: Results From A Community Water Education Program}

\author{
By: Kristan Cockerill
}

\begin{abstract}
Based on feedback from attendees at an environmental summit who requested information about regional water sources, a team comprised of a local nonprofit, a state university, and a cooperative extension office created a community water education program. Undergraduate student interns worked with the author to develop a 20-minute science-based presentation that was delivered in 14 different venues in a three-county region of northwestern North Carolina. Following each presentation there was a discussion session that highlighted questions about how water works and community concerns about water availability and management. Program evaluations reflect that people believed they better understood the science related to water quantity and that the key messages in the program were important to their communities.
\end{abstract}

Kristan Cockerill (2010) Communicating How Water Works: Results From a Community Water Education Program, The Journal of Environmental Education, 41:3, 151-164, DOI: 10.1080/00958960903295266. Publisher version of record available at: https://www.tandfonline.com/doi/full/10.1080/00958960903295266 


\title{
Communicating How Water Works: Results From a Community Water Education Program
}

\author{
Kristan Cockerill \\ Appalachian State University, Boone, North Carolina, USA
}

\begin{abstract}
Based on feedback from attendees at an environmental summit who requested information about regional water sources, a team comprised of a local nonprofit, a state university, and a cooperative extension office created a community water education program. Undergraduate student interns worked with the author to develop a 20-minute science-based presentation that was delivered in 14 different venues in a three-county region of northwestern North Carolina. Following each presentation there was a discussion session that highlighted questions about how water works and community concerns about water availability and management. Program evaluations reflect that people believed they better understood the science related to water quantity and that the key messages in the program were important to their communities.
\end{abstract}

Keywords collaborative, community education, community engagement, science communication, water

Headlines threaten that we are "running out of water" and debates over access to water intensify worldwide as supplies face increasing pressure. Anyone who has delivered a public presentation or taught an introductory course about water quickly discovers that there is limited understanding of specific concepts such as the hydrocycle (hence the prevalent notion that we can literally, run out of water). Experience in the classroom confirms that water literacy is low among students of all ages (Ewing \& Mills, 1994; Dickerson, Penick, Dawkins, \& van Sickle, 2007; Shepardson, Wee, Priddy, Schellenberger, \& Harbor, 2007; Covitt, Gunckel, \& Anderson, 2009). Although research on adult water literacy is lacking, the low level of literacy among students likely results in an ill-informed general populace. Perpetuating this cycle, empirical studies about water education show that some teachers feel they lack adequate knowledge to integrate water resources into their classrooms (Brody, 1995). Coyle (2005, p. ix), in summarizing the state of environmental literacy, says, "The average American adult, regardless of age, income, or level of education, mostly fails

Correspondence should be sent to Kristan Cockerill, Living Learning Center, University College, Appalachian State University, ASU Box 32080, Boone, NC 28608, USA. E-mail: cockerillkm@appstate.edu 
to grasp essential aspects of environmental science, important cause/effect relationships, or even basic concepts such as runoff pollution, power generation and fuel use, or water flow patterns." This has societal implications; for example, public reaction to water shortages often reflects a lack of understanding about water and how it works (Smakhtin \& Schipper, 2008).

Not understanding our water system helps to explain the evidence that people are reluctant to assess their own role in water issues (DeLorme, Hagen, \& Stout, 2003; Coyle, 2005). Griffin and Mjelde (2000) found that people in the United States have a sense of entitlement toward water and view water bills as a "tax" rather than as an "invoice for the on-demand delivery of treated, pressurized tap water" (p. 425). Because water is relatively cheap, people do not typically know how much they or their various appliances use (Griffin \& Mjelde, 2000). This perhaps reflects the lack of priority we give this resource. For the vast majority of Americans, water is an "on demand" resource because the United States does have abundant supplies and significant infrastructure to ensure that when we turn on our taps, copious amounts of clean water are readily available. Therefore, our water supply system is "invisible" and how water works independent of our use is largely uncontemplated. Yet, people make decisions related to individual water use as well as decisions about community development that have far-reaching implications for our water supply. Increasing knowledge of water's natural system as well as our use of the resource could have positive impacts on diverse policy decisions relevant to our water supply.

\section{PROGRAM BACKGROUND}

In northwestern North Carolina, concern about water was expressed in a 2005 Environment Summit hosted by the nonprofit group, MountainKeepers. At this gathering, attendees, who clearly had an interest in environmental issues, admitted that although they recognized how important water is, they felt they knew little about the region's water supply. In response, MountainKeepers successfully applied for an Environmental Education Grant from the U.S. Environmental Protection Agency to develop a community water education program. Program goals included:

- To develop a presentation and supporting informational materials to help community leaders and residents better understand the science related to the global water system and its relationship to our lives.

- To generate a discussion with and among those who attend the presentation to identify ongoing water-related efforts within the communities and facilitate linkages among communities, civic groups, and university projects to enable communities to leverage resources and share knowledge to better address water supply concerns.

- To establish an exhibit about water at the McKinney Geology Teaching Museum at Appalachian State University (ASU) and to offer the developed educational materials through the museum and the Watauga County Cooperative Extension Office to serve as a continuing source for people to learn more about regional water conditions.

The short-term outcomes stated in the grant proposal were to generate a better understanding of the geology and hydrology in the region as well as increase knowledge about water issues, programs, and policies in various communities. This project accepted evidence that scientific discourse can differ significantly from public discourse (Morgan, 2003; Lee \& Roth, 2006) and therefore, simply providing scientific information using scientific language would not lead 
to learning or to encouraging discussion. Program development, therefore, sought consilience among the scientific and public discourse (Wilson, 1998). The program design recognized communication as a complex process rather than a one-way transmission and was structured to enable more productive exchange of science-based information by engaging participants in a discussion about water (Weber \& Word, 2001). Through the discussion, the author could ascertain whether participants possessed an accurate understanding of basic hydrologic concepts or if particular terms or concepts had taken an unintended, maybe inaccurate, turn and offer additional information or gentle correction to enhance learning. Because the target audience represented a diverse population and because the discussion portion of the program was as important as the presentation, there was the potential for each session to generate unique examples of incidental, broad, and/or reaffirming learning (Storksdiek, Ellenbogen, \& Heimlich, 2005). The intent was not simply to disseminate scientific information in hopes of increasing knowledge, but to encourage participants to link that knowledge to individual and community needs (Roth \& Lee, 2004). As friends, neighbors, and acquaintances together explored the science inherent in water supply issues, they also would explore ideas about how to manage water and what value it had in their community.

This program was unique in that it focused on water quantity. Informal interaction with hydrologists and Cooperative Extension professionals revealed that water quantity had historically not been emphasized in this region. Although unquantified, literature reviews for this project reflect more attention in academic and popular literature on water quality than water quantity. Federal water regulations include the Clean Water Act and the Safe Drinking Water Act with no equivalents for assessing or protecting water quantity. Research on public knowledge has also focused more on quality (Arcury \& Johnson, 1987; Coyle, 2005; Clay et al., 2007). In public opinion polls, water quality ranks higher in public concern than water quantity issues, even in arid climates (Institute for Public Policy, 1995, 2000; Mahler, Simmons, Sorensen, \& Miner, 2004). This may reflect the historic water abundance such that contaminants have been a greater perceived threat than the amount of water available. In addition, because quality is more regulated, it is potentially more newsworthy and more likely to be the subject of research. Of course, quality and quantity are interrelated, but the lack of attention to quantity and the physical realities of water is a gap that this project endeavored to address.

The target audience included urban and rural residents in Watauga, Ashe, and Avery counties in northwestern North Carolina. The total population of the region is almost 88,000 with Watauga County accounting for about half of this total. The Town of Boone is home to ASU and represents the single largest "urban" area with a population of about 15,000 permanent residents. The university is by far the largest employer in this region and has grown from just over 10,000 students in 1980 to more than 16,000 in 2009 (ASU, 2009). This mountainous area averages more than 50 inches of rain per year and about 40 inches of snow and is the headwaters for several large rivers. Tourism, including water-based recreation activities like skiing and whitewater rafting are key to the region's economy and contribute to increased development in the form of hotels and restaurants. Furthermore, vacation homes are an economic driver as well as a growing concern among long-term residents (Watauga Economic Development Center, 2009). Much of the state, including this region, experienced extreme drought conditions in 2007 and continued to be drier than normal through early 2009 (NC Drought Management Advisory Council, 2009). The drought conditions raised concerns about long-term water availability and prompted state-level action, including passage of a "drought bill" in 2008 to give the governor more authority to work with 
local communities to address water shortages and to improve water planning in the state (North Carolina SL 2008-143). In 2009 the state legislature created a Water Resources and Infrastructure committee. In the study region communities adopted or expanded water conservation programs. Throughout 2007 regional newspapers consistently featured articles related to the drought and the local water supply. In addition, contentious debates related to water and development became a main theme in the 2008 local elections.

\section{PROGRAM DEVELOPMENT}

The project was a cooperative endeavor among MountainKeepers, ASU, and the Watauga County Cooperative Extension Office. MountainKeepers and Extension are trusted sources of information and they took responsibility for contacting community groups to schedule presentations. This proved invaluable, because this area is characterized by a fair bit of tension between the state university and the rural communities. MountainKeepers and Extension were able to open doors that someone from the university may not have been able to open. This experience confirmed Mahler, Simmons, and Sorensen's (2005) point that, for rural residents, Extension is a more used resource than are universities.

Five undergraduate interns formed the core of the team that generated the "How Water Works" presentation. The author worked with the MountainKeepers Board of Directors to host a competitive search for students who represented four academic departments: anthropology; geography and planning; geology; and sustainable development. The author met with the interns weekly from January through April 2008. In the initial weeks of the project, the author encouraged the students to read all that they could about water quantity in the region, to seek informative graphics related to water, and to think about how to "teach" what they were learning to others. The interns reviewed ongoing research projects related to water quantity, media coverage of regional water issues, and dozens of images. They unsuccessfully sought examples of other student-driven public education efforts. At each meeting the students and the author discussed the information and images and their pertinence to this project. Several weeks into the project, after the students had immersed themselves in the water relevant information, the author led a brainstorming session with them to identify what key messages they had gleaned and what they thought the presentation should include. Then the author shared with the students feedback she had gathered from several hydrologists as to what they believed were key points relevant to the region's hydrology. From the list of ideas they had generated, supplemented with input from hydrologists, the students established the tone and the overall content for the program. The team agreed that as people with relatively limited knowledge about water supply issues, particularly in northwestern North Carolina, the students were well positioned to offer insight into what concepts and what language would best integrate the scientific and public discourse on water for this region.

To meet the program goal of generating a better understanding of the geology and hydrology, the team agreed that it was crucial to 'translate' the scientific information to make it accessible to a general audience. At the same time, an overarching philosophical approach was to make the complexity inherent in water systems and the uncertainties surrounding the water supply in this region explicit. Building on work in science communication, the team agreed that it was essential to put the science into context so that people could see its relevance to them personally and to their communities (Cockerill, 2002; Hayes \& Grossman, 2006). Because development is 
a driving economic force in the region and its relationship to the water supply was a contentious issue in the 2008 election, the students suggested that this offered an excellent way to connect the science to people's experience. The team developed three key messages for the presentation and supporting materials:

- How Water Works - This message included the basic elements of the hydrological cycle (called the water cycle in the presentation). Specifically the presentation noted that this is a global system with local impacts, that the amount of water is relatively constant on the planet, and that all water is interconnected in the system. It emphasized surface and groundwater interactions and the properties of groundwater storage and movement. This message also encompassed the fact that river basin boundaries do not respect political boundaries and that drought and floods are part of how water works.

- How We Use Water-This message covered the general connections between water supply and development, specifically the formation of cones of depression and the impacts from impervious surfaces. It covered average household water use in the United States compared to global use and highlighted differences in how the three counties in the target region use water.

- Lack of Regional Data and Ongoing Research-A key message through the entire presentation was that there is limited data generally, and for this region in particular and therefore there is significant uncertainty surrounding long-term supplies and human use. The presentation concluded by noting that numerous studies are underway to better understand the regional water supply and summarized several of these.

The students and the author revisited the images and selected those most relevant and the students procured copyright permission to use them in the presentation. They also compiled demographic data for the region and produced original graphics to show county level water use, population and development trends, as well as maps showing political boundaries overlain on river basins. The students each generated sample slides with design as well as content elements. From these the author put together a draft presentation, which the students critiqued. After several iterations, including a trial presentation to the MountainKeepers Board of Directors and Extension personnel, the group settled on a final presentation. This process was repeated to develop the program brochure. In addition to MountainKeepers and Extension review, all materials were vetted with hydrologists from ASU as well as state and federal agencies.

The program content was intended to be informative, not prescriptive. This approach is premised on the evidence that there are not clear positive relationships among increased education and actually generating behavior modification (Ribaudo \& Horan, 1999; Wagenet, Pfeffer, Sutphin, \& Stycos, 1999). Coyle (2005) notes that although there is a high awareness of environmental issues among the U.S. populace, this has little effect on changing behavior. In addition, the existing controversy related to development in this region led the team to conclude that any appearance of "taking sides" would be counter productive. The project team also agreed that the lack of comprehensive data in this region makes specific recommendations inappropriate. Therefore, this program did not identify or encourage any particular action. The primary goal was to offer relevant, accurate information that would increase the level of understanding about how water works. Although this may not directly affect individual behavior, it may increase support for research efforts and/or policy making relevant to addressing water supply concerns 
(Coyle, 2005). The project team anticipated that the presentation combined with a discussion would encourage participants to reflect on individual roles as well as community roles in water supply issues.

\section{METHOD}

In total, 14 presentations were delivered between April and June 2008; eight to coincide with existing meetings of various civic groups, including Kiwanis, Rotary, and Volunteer Fire Departments. As this is a rural region, most people rely on volunteer fire service and the firehouses are public gathering sites. These fire departments utilize surface water sources to fill their tank trucks and hence have a strong interest in water quantity. Six sessions, two in each county, were open to the general public. These were held in Extension offices, public libraries, and other community-based venues. Several sessions were during the day and several were in the evening. The author delivered the presentations and encouraged questions and discussion. A student intern or the author took notes during or immediately after each session to identify questions asked, discussion topics raised, and the general tone of the session.

Ideally this project would have conducted pre- and postassessments of actual knowledge levels among program attendees. But, because a key objective of this effort was to reach out to diverse communities and to generate a discussion, there was a legitimate concern with alienating some communities if the program appeared too "academic." Therefore, the team agreed that a postpresentation evaluation coupled with notes from the discussions would provide sufficient feedback on the program's impact. The evaluation questions sought feedback on the presentation itself (e.g., Was it clear? Was it what was expected?), on whether people felt they learned anything, as well as information on whether the key ideas in the presentation were relevant to the respondent's community. The evaluations also collected demographic data including county of residence, water source, gender, age, and length of residence in the region.

The presentation is about 20-minutes long, but the meetings generally lasted an hour as people asked numerous questions and did engage in significant discussion. Of the 240 people who attended, 145 provided feedback on evaluation forms (61\% response rate). This somewhat low response rate is potentially an unintended consequence of success. Because many of the presentations occurred as part of a regularly scheduled meeting with an endpoint, attendees often needed to leave before completing the evaluation. The lively discussions kept people engaged instead of focused on completing the evaluation. At each civic group session, several people stopped briefly on their way out to say they did not have time to complete the evaluation but wanted to say they enjoyed the program.

\section{RESULTS}

Although the program was widely advertised via local newspapers, radio, e-mail, and posted flyers, attendance at the public meetings was quite low (40 of the 240 total attendees). There are several potential explanations for this low turnout. One is that summertime is busy with many events competing for public attention. Another is that the drought pressures had eased a bit and water was generally receiving less media coverage at this time. Most communities in this area did 
TABLE 1

Distribution of Program Attendees by County and Household Water Source $(n=145)$

\begin{tabular}{lc}
\hline & \% of respondents \\
\hline County & \\
Ashe & 10.3 \\
Avery & 2.1 \\
Watauga & 71.7 \\
Other & 6.2 \\
No answer & 9.7 \\
Total & 100.0 \\
Household water source & \\
City water & 15.9 \\
Private well & 45.5 \\
Shared well & 15.9 \\
Spring & 11.0 \\
Don't know & 0.7 \\
No answer & 11.0 \\
Total & 100.0 \\
\hline
\end{tabular}

not reach a critical point that required mandatory water use restrictions, so despite the drought, lifestyle was not compromised.

The program, however, did directly reach 200 individuals via the civic groups. As Table 1 shows, although Watauga County did dominate attendance, all three counties were represented. The attendees well represent the diversity of water supply mechanisms in this region with $16 \%$ of attendees receiving their water from a city supply, $62 \%$ utilizing private or shared domestic wells, and $11 \%$ using spring water.

The reaction to this program was overwhelmingly positive. Table 2 shows the responses to general evaluation questions. Respondents were asked to "agree" or "disagree" with the various statements and were offered space to offer comments. Although this program did not explicitly assess knowledge gains, it did include a self-assessment of whether learning occurred. More than half of the respondents reported that something in the program differed from their previous ideas about water. Of course, it is feasible that they rejected the information from this program and

TABLE 2

Program Evaluation Responses $(n=145)$

\begin{tabular}{lcccc}
\hline Evaluation statement & Agree\% & Disagree\% & No answer\% & Total \\
\hline $\begin{array}{l}\text { All of the information was clearly presented. } \\
\begin{array}{l}\text { I have a clearer understanding of how water works than I did } \\
\quad \text { before this presentation. }\end{array}\end{array}$ & 99.3 & 0.7 & 0.0 & 100 \\
$\begin{array}{l}\text { This program focused on information that I expected to see } \\
\quad \text { presented. }\end{array}$ & 91.0 & 5.5 & 3.8 & 100 \\
$\begin{array}{l}\text { Some information presented here differed from my previous ideas } \\
\quad \text { about how water works. }\end{array}$ & 52.4 & 40.7 & 6.9 & 100 \\
\hline
\end{tabular}


retained their previous ideas. However, the $97 \%$ agreement with the statement "I have a clearer understanding of how water works than I did before this presentation" suggests that the new information was accepted and clarified or challenged previous ideas. Twenty-eight respondents offered additional comments related to what they had learned from this program and these focused on specific concepts, most commonly recharge, cone of depression, and the global nature of the water system.

Overall, 35 separate respondents $(14.5 \%)$ offered general comments related to one or more of the evaluation statements. The majority of these respondents wrote variations on "excellent" or "nice graphics." Several people commented that they expected information about water quality. This was not unexpected given that quality is the more common focus for water information. Several other people indicated that they expected more specific information about water conservation to be presented. Given the drought conditions, this was not surprising.

The slide showing average U.S. water use compared to global water use generated a strong reaction in every session. Several people made a comment on the evaluation, noting that they were surprised at how much water we use in the United States. Confirming Delorme et al. (2003) and Coyle (2005), however, people seemed unwilling to accept their role in this water use. In each session at least one person stated that there was "no way" that they used as much as the national average. For some, this is likely true, but still, this response does reflect the lack of introspection about personal water use. At one of the urban presentations, several people got into a discussion about how the use amounts were measured and one person said, "Every time you bring up numbers you have to think about what they are including." This reflects both an understanding of the potential to manipulate data and potentially seeking justification for why their perceived personal use could not be what the reported data show.

At about half of the meetings at least one person told the author that they had heard other talks about water and the science went "over their heads" but this program made the science understandable. This feedback is consistent with the broad body of work on science communication showing that there is often a "translation" issue in finding appropriate language, metaphor, and/or graphics to clearly explain scientific information (Tannenbaum, 1963; Dunbar, 1995; Hartz \& Chappell, 1997; Chandler, 2001; Weber \& Word, 2001; Hayes \& Grossman, 2006). The positive comments indicate that this program was perhaps more successful than others in offering accessible scientific information. Still, comments on the evaluation forms and notes from the discussions offer evidence of several concepts that people consistently struggled to comprehend. These results are consistent with previous work on water literacy (Meyer, 1987; Dickerson et al., 2007; Covitt et al., 2009). First, there remains a prevalent notion that an aquifer is equivalent to an underground lake or river. It is difficult for people to grasp the idea of water moving through rock. This manifested in questions at half the meetings about why wells fairly close together could generate disparate productivity and one suggestion to "blast a hole" underground to allow water to accumulate into an underground lake. Second, the connections between surface water and ground water are not intuitive. Attendees at all but two meetings reported anecdotal evidence of springs going dry and blaming increased well drilling from new housing developments. At the same time, there were questions about the potential for drilling new wells to augment or replace water not available in area rivers due to the drought. Finally, the connections between the global hydrological cycle and local effects were a point of discussion at five of the meetings. These sessions elicited such questions as, "If there is the same amount of water as always, why are we in a drought?" 
In responding to questions the author reiterated key elements of the hydrocycle including its global function and groundwater/surface water interactions. Although misconceptions undoubtedly remain, the general sense from these discussions was that attendees were developing a more complex understanding of water systems. In several discussions, attendees accurately responded to each other's questions, offering support for the conclusion that learning had occurred. In every session people shared information about water issues and concerns in their community. As anticipated, the specifics of these discussions did vary from session to session. In an early meeting, a group of firefighters shared that they had suffered from water shortages jeopardizing their firefighting ability. One firefighter said that access to water was still "not good and we are looking for new sources." In each of the rural sessions participants talked among themselves about how water use had changed in their communities and told stories of wells and springs going dry over the years or of building new houses and being unable to establish a productive well. In the two most urban settings people raised ideas for public education to encourage water conservation (this in spite of the point already made that at every session attendees were surprised by and questioned the average water use in the United States). One person noted that water conservation/awareness is like smoking and that "everyone used to smoke" but ad campaigns have changed the public perception of smoking. This implication indicated that water waste should be made socially unacceptable.

Attendees in about half of the sessions raised ideas for policy development and discussed rumors about future regulations. Individuals in several discussions noted that the presentation should be delivered to all elected officials in the region. In urban settings there seemed to be support for increasing water-related regulations as individuals in these sessions raised the idea of restricting specific types of water use in a drought or requiring wells to be registered before they are installed. In the rural areas participants seemed more skeptical about rules on water use. At one rural meeting a gentleman reported to the group that a rumor in his community was that the state wanted people to register their wells "so that the state could require people to share water during dry times." Water use related to development was raised as a concern in both urban and rural settings. One person in a rural community said, "People come and they just expect the water to be here." At that same meeting, another person noted that the "program should be presented to city planning boards and town councils. These are the powers that can control growth and limit permits. To talk to small community groups is not going to get results. We have no power over builders coming in and building hundreds of homes." In response to this, other participants did suggest that citizens do have the ability to influence the decision makers. In one discussion a town council member from one community and a town manager from a neighboring community shared information with each other about their water management efforts. This program offered a venue and the basic understanding of water processes to prompt this exchange.

Table 3 shows respondent reactions to how relevant the presentation's key messages were to their communities. Confirming Coyle's (2005) ideas about literacy programs generating support for research, more than $73 \%$ of respondents indicated that ongoing research was "very important" to decision making in their community. The specific research projects highlighted in the presentation were countywide inventories to locate wells and document their productivity; stream monitoring to better understand the effects of development on mountain streams as well as the groundwater/surface water relationships; a local well-monitoring program to show reliability and flow trends over time; and models to assess the relationships between recharge rates and development density. Although this positive response bodes well for garnering public support to continue 
TABLE 3

Program Relevance to Community Decision Making $(n=145)$

\begin{tabular}{|c|c|c|c|c|c|c|c|}
\hline $\begin{array}{l}\text { How would you rank each of the following } \\
\text { topics covered in this presentation } \\
\text { in terms of its importance in making } \\
\text { decisions about water in your community? } \\
\text { Scale }\end{array}$ & $\begin{array}{c}\text { Not } \\
\text { important } \\
\% \\
1\end{array}$ & $\begin{array}{c}\% \\
2\end{array}$ & $\begin{array}{c}\% \\
3\end{array}$ & $\begin{array}{l}\% \\
4\end{array}$ & $\begin{array}{c}\text { Very } \\
\text { important } \\
\% \\
5\end{array}$ & $\begin{array}{c}\text { No } \\
\text { answer } \\
\%\end{array}$ & Total \\
\hline Water cycle & 2.8 & 2.1 & 11.7 & 26.9 & 56.6 & 0.0 & 100 \\
\hline Connections between surface and groundwater & 1.4 & 2.1 & 12.4 & 20 & 64.1 & 0.0 & 100 \\
\hline Thinking about water and development & 2.8 & 2.1 & 5.5 & 23.4 & 65.5 & 0.7 & 100 \\
\hline Lack of water-related data & 1.4 & 2.1 & 8.3 & 24.1 & 64.1 & 0.0 & 100 \\
\hline Ongoing research & 2.1 & 0.7 & 4.1 & 18.6 & 73.1 & 1.4 & 100 \\
\hline
\end{tabular}

these types of research efforts, this evaluation did not assess who should pay for research or what should be done with the data generated.

Interestingly, the current lack of data was deemed less important than ongoing research. In several discussions, individuals noted that they were surprised at the level of uncertainty in our understanding of the geology and hydrology in this region. Perhaps respondents recognize that, out of necessity, decisions are being made despite the lack of data and there has not yet been a crisis in this region. At the same time, they recognize that the lack of data may have future implications and therefore pursuing research makes sense.

The "water cycle" was deemed the least important idea from the presentation with only about $57 \%$ of respondents deeming it "very important." This may reflect a sense of the global and uncontrollable nature of the system. Roth and Lee's (2004) work might suggest that respondents feel that the other key points are more directly related to respondents' everyday lives and community decision making. Or perhaps the hydrocycle remains confusing and therefore people discount its relevance.

In comparing respondent demographic information with their responses to these ideas, only gender showed any significant relationship. The respondents were strongly skewed toward men (62\%) largely because of the presentations in the volunteer fire departments. On the 1 to 5 scale, with 1 being "not important" and 5 being "very important," no women responded that any topic was a 1 or 2 and women were more likely to respond that these all rated a 5 (Table 4). This response is consistent with research on gender and pro-environmental attitudes and behavior. In their review of the literature from 1988-1998, Zelezny, Chua, and Aldrich (2000) found that in most studies women report more general environmental concern than men. Their study concluded that women were more likely to be socialized to be socially responsible, and hence reported higher pro-environmental behavior.

A version of the presentation with a script embedded is now part of the exhibits at the McKinney Geology Teaching Museum and there is a brochure and a CD available in the museum and at the Extension Office. The CD includes the presentation, a summary of the questions and discussions from the program, as well as sources for additional information. The CD has been mailed to all county and town governing bodies in the three-county area and has been shared with middle school science teachers. 
TABLE 4

Differences Between Male and Female Respondents to Program Evaluation Questions About the Importance of Key Messages in Their Communities. ( $n=90$ male; 55 female)

\begin{tabular}{|c|c|c|c|c|c|c|}
\hline \multirow{2}{*}{$\begin{array}{l}\text { Scale } \\
\% \text { of male vs. female responses }\end{array}$} & \multicolumn{2}{|c|}{$\begin{array}{c}1-2 \\
\text { Not Important }\end{array}$} & \multicolumn{2}{|c|}{$\begin{array}{c}3 \\
\text { Neutral }\end{array}$} & \multicolumn{2}{|c|}{$\begin{array}{c}4-5 \\
\text { Important }\end{array}$} \\
\hline & $M$ & $F$ & $M$ & $F$ & $M$ & $F$ \\
\hline Water cycle* & $8 \%$ & 0 & $13 \%$ & $8 \%$ & $79 \%$ & $93 \%$ \\
\hline Surface/groundwater connections* & $6 \%$ & 0 & $16 \%$ & $8 \%$ & $79 \%$ & $93 \%$ \\
\hline Water and development* & $7 \%$ & 0 & $9 \%$ & $0 \%$ & $84 \%$ & $100 \%$ \\
\hline Lack of data* & $6 \%$ & 0 & $11 \%$ & $3 \%$ & $83 \%$ & $98 \%$ \\
\hline Ongoing research & $4 \%$ & 0 & $6 \%$ & $0 \%$ & $90 \%$ & $100 \%$ \\
\hline
\end{tabular}

*t-test shows significance, $p<.05$.

\section{DISCUSSION}

This program exceeded expectations and met the goals established at the outset. It successfully employed student interns to develop the community water education materials. Working with undergraduates was time intensive, but did result in a second level of education, as this group of students learned firsthand about the difficulties and importance of developing science-based public information materials. The students also served well as a proxy for the public in terms of "translating" scientific information. If they read a report or reviewed a graphic and did not understand it or did not find it relevant, then it was likely that the target audience would have a similar reaction. On a pragmatic level, undergraduate interns with proper supervision offer a high number of person hours at a relatively low expense. This method could be replicated in any community with a college or university.

Establishing a team among the university, the nonprofit and the Extension Office was invaluable and this project would not have been as successful without this collaboration. While the partnership is important, it does increase the management logistics and it is extremely important to clearly delineate responsibilities for each team member at the outset. A key benefit of the team approach is to leverage the skills that each partner brings. Determining who is best suited to serve on a team will be location dependent. Therefore, it is essential to know the region and the population being targeted and work with that knowledge. As already noted, in this project, the university alone could not have readily gained access to some of the more rural communities and recognizing this was important to this program's success. Scheduling the program with existing civic groups was clearly more effective than holding general public gatherings. Besides the readymade audience, offering information through the civic groups likely has had a multiplier effect, as members of these groups are leaders in their communities and able to further disseminate their newfound knowledge.

Most important, this program did seem to enhance learning and it definitely generated discussion. Based on evaluation responses, people perceived that they do better understand the science behind water supply issues. Of course, without an assessment of actual knowledge, this cannot be verified, but the questions that attendees asked during the discussions do offer insight into what concepts are difficult and how the information in this program challenged previously held ideas. 
The experience with this project confirms previous work that in developing community education it is important to make the science accessible (cf Weber \& Word, 2001; Hays \& Grossman, 2006). As some of the respondents indicated, they had heard this information before, but did not "get it" until they attended this program. As sound communication practice would suggest, the discussions made it clear that having just a few key messages that could be reinforced in the discussion was important to successfully communicate with the audience. Having well-chosen images was also important and revisiting the images during the discussion helped to reinforce the initial message.

Keeping the focus on information about how water works and not specifically advocating any particular policy action was an appropriate approach as there is apprehension in many of these communities about government or noncommunity intervention of any kind. In fact, at one session, the author explained that researchers are trying to identify well locations in the region and that one way to help further the research is to allow researchers access to private wells. At the back of the room a young man imitated the sound of loading a shotgun. While this response was an anomaly for this project, the reality is that the researchers have faced actual shotguns as they pursued their well inventory. Programs like this may help those individuals see that better understanding how water works can be of value to their communities and that research efforts might contribute to their local decision making without outside intervention.

Early in the project the team agreed that 20 minutes was the maximum length for the presentation so that there would be adequate time for questions and this proved to be a wise decision as perhaps the most important outcome was that this program did generate significant discussion. Most attendees were clearly interested in understanding the science and in identifying how to apply that knowledge to the issues in their communities. Keeping the formal presentation focused on information rather than advocacy allowed attendees to explore their own ideas about action and to clarify the relationships among potential actions and the physical reality of water processes. These conversations form the basis from which these communities can generate an even stronger understanding of water and potentially move that understanding toward action of their own design. Experience in collaborative processes shows that when people engage in discussion among themselves and with technical experts to better understand a complex issue, they become vested in the process and that can translate into changed attitudes and more informed decision making (McDaniels, Gregory, \& Fields, 1999; Cockerill, Passell, \& Tidwell, 2006; Borden, Cline, Hussey, Longsworth, \& Mancinelli, 2007). Perhaps the conversation at the one session between decision makers in neighboring towns might serve as a model and encourage those individuals to promote a broader conversation among their respective communities about water. Because the participants in this program began generating their own ideas for what could or should be done, based on their increased understanding of how water works, there is a stronger likelihood that this may result in political support for land use planning measures that protect the water supply or increased water reporting requirements or other water quantity policy actions. If additional programs like this were conducted to reach more people, and to perhaps facilitate sessions that brought together the general public and the decision makers (i.e., elected/appointed officials) it could establish a baseline level of understanding across the region. Then, as the state and local governments continue to face challenges in managing water supplies, perhaps the knowledge that community members have gained will help both the decision makers and the public to more clearly assess proposed regulations and policies. 


\section{SUMMARY}

As the strain on water resources continues to grow throughout the world, educating people about how water works will become increasingly important. This project offers one example of a successful effort toward that end. Because water is a global system with diverse local uses and effects, educational materials do need to be tailored for each location, but this project does provide insight for others seeking to pursue their own community education efforts. Universal lessons include the need to translate scientific information for a general audience, to offer an opportunity for questions and discussion as that may be where learning actually occurs, and to utilize a team approach to leverage the skills and access that various entities will have in any particular community.

\section{ACKNOWLEDGMENTS}

Daniel Cobb, Melody Heath, Kaitlin Marone, Max Sigler, and Rachel Storniolo provided a constant reality check while developing the community education materials. Wendy Patoprsty at the Watauga County Cooperative Extension Office and all the members of the MountainKeepers Board of Directors were key to the program's success. The program was funded through a grant from the U.S. Environmental Protection Agency, Assistance ID No. 96483107. Anonymous review comments greatly improved this article.

\section{REFERENCES}

Appalachian State University (2009). Appalachian State University. Retrieved March 11, 2009, from http://www.appstate. edu/about/

Arcury, T. A. \& Johnson, T. P. (1987). Public environmental knowledge: A statewide survey. Journal of Environmental Education, 18(4), 31-37.

Borden, R. J., Cline, K. S., Hussey, T., Longsworth, G., \& Mancinelli, I. (2007). A river runs through it: A collegecommunity collaboration for watershed-based regional planning and education. Human Ecology Review, 14(1), 90-100.

Brody, M. (1995). Development of a curriculum framework for water education for educators, scientists, and resource managers. Journal of Environmental Education, 26(4), 18-29.

Chandler, D. L. (2001, June 19). Familiar images make false impressions. Boston Globe, p. Cl.

Clay, D. E., Ren, C., Reese, C., Waskom, R., Bauder, J., Mesner, N., et al. (2007). Linking public attitudes with perceptions of factors impacting water quality and attending learning activities. Journal of Natural Resources \& Life Sciences Education, 36(1), 36-44.

Cockerill, K. (2002). Context is key: The media role in shaping public perceptions about environmental issues. Environmental Practice, 2(1), 107-113.

Cockerill, K., Passell, H., \& Tidwell, V. (2006). Cooperative modeling: Building bridges between science and the public. Journal of the American Water Resources Association, 42(2), 457-471.

Covitt, B. A., Gunckel, K. L., \& Anderson, C. W. (2009). Students' developing understanding of water in environmental systems. Journal of Environmental Education, 40(3), 37-51.

Coyle, K. (2005). Environmental literacy in America. Washington, DC: The National Environmental Education \& Training Foundation.

DeLorme, D. E., Hagen, S. C., \& Stout, I. J. (2003). Consumers' perspectives on water issues: Directions for educational campaigns. The Journal of Environmental Education, 34(2), 28-35.

Dickerson, D. L., Penick, J. E., Dawkins, K. R., \& Van Sickle, M. (2007). Groundwater in science education. Journal of Science Teacher Education, 18, 45-61. 
Dunbar, R. (1995). The trouble with science. Cambridge, MA: Harvard University Press.

Ewing, M. S. \& Mills, T. J. (1994). Water literacy in college freshmen: Could a cognitive imagery strategy improve understanding? Journal of Environmental Education, 25(4), 36-40.

Griffin, R. C. \& Mjelde, J. W. (2000). Valuing water supply reliability. American Journal of Agricultural Economics, $82(2), 414-426$.

Hartz, J. \& Chappell, R. (1997). Worlds apart: How the distance between science and journalism threatens America's future. Nashville, TN: First Amendment Center.

Hayes, R. \& Grossman, D. (2006). A scientist's guide to talking with the media. New Brunswick, NJ: Rutgers University Press.

Institute for Public Policy (IPP). (1995). Water in New Mexico. Quarterly Profile of New Mexico Citizens, 7(2), 1-3.

Institute for Public Policy (IPP). (2000). Water issues in New Mexico and the Middle Rio Grande. Public Opinion Profile of New Mexico Citizens, 12(2), 1-3.

Lee, S. \& Roth, W. M. (2006). Community-level controversy over a natural resource: Toward a more democratic science in society. Society and Natural Resources, 19, 429-445.

Mahler, R. L., Simmons, R., \& Sorensen, F. (2005). Public perceptions and actions towards sustainable groundwater management in the Pacific Northwest region, USA. Water Resources Development, 21(3), 465-472.

Mahler, R. L., Simmons, R., Sorensen, F., \& Miner, J. R. (2004). Priority water issues in the Pacific Northwest. Journal of Extension, 42(5). Retrieved April 26, 2008, from http://www.joe.org/joe/2004october/index.php

McDaniels, T. L., Gregory, R. S., \& Fields, D. (1999). Democratizing risk management: Successful public involvement in local water management decisions. Risk Analysis, 19(3), 497-510.

Meyer, W. B. (1987). Vernacular American theories of earth science. Journal of Geological Education, 35(4), 193-196.

Morgan, E. L. (2003). Discourses of water: A framework for the study of environmental communication. Applied Environmental Education and Communication, 2, 153-159.

NC Drought Management Advisory Council (2009). Retrieved March 11, 2009, from http://www.ncdrought.org/

North Carolina Session Law 2008-143 (2008). Retrieved March 11, 2009, from http://www.ncleg.net/Sessions/2007/ Bills/House/HTML/H2499v6.html

Ribaudo, M. O. \& Horan, R. D. (1999). The role of education in nonpoint source pollution control policy. Review of Agricultural Economics, 21(2), 331-343.

Roth, W. M. \& Lee, S. (2004). Science education as/for participation in the community. Science Education, 88, $263-291$.

Shepardson, D. P., Wee, B., Priddy, M., Schellenberger, L., \& Harbor, J. (2007). What is a watershed? Implications of student conceptions for environmental science education and the National Science Education Standards. Science Education, 91(4), 554-578.

Smakhtin, V. U. \& Schipper, E. L. F. (2008). Droughts: The impact of semantics and perceptions. Water Policy, 10, 131-143.

Storksdieck, M., Ellenbogen, K., \& Heimlich, J. E. (2005). Changing minds? Reassessing outcomes in free-choice environmental education. Environmental Education Research, 11(3), 353-369.

Tannenbaum, P. H. (1963). Communication of science information. Science, 140(3567), 579-583.

Wagenet, L. P., Pfeffer, M. J., Sutphin, H. D., \& Stycos, J. M. (1999). Adult education and watershed knowledge in upstate New York. Journal of the American Water Resources Association, 35(3), 609-621.

Watauga Economic Development Center (2009). Retrieved March 11, 2009, from http://wataugaedc.org/demo1.html

Weber, J. R. \& Word, C. S. (2001). The communication process as evaluative context: What do nonscientists hear when scientists speak? BioScience, 51(6), 487-495.

Wilson, E. O. (1998). Consilience: The unity of knowledge. New York: Alfred A. Knopf, Inc.

Zelezny, L. C., Chua, P. P., \& Aldrich, C. (2000). Elaborating on gender differences in environmentalism. Journal of Social Issues, 56(3), 443-457. 